\title{
ASSOCIATION BETWEEN A31GSNP OF THE MYOSTATIN GENE AND SERUM LEVELS OF ALP, GOT, $P$ AND CA IN EGYPTIAN BUFFALO (BUBALUS BUBALIS)
}

\author{
Michel Fahmy Saad ${ }^{a}$, Shawky Mahmoud ${ }^{a}$, Mohammed Abu El-Magd $^{b}$ \\ and Rasha Alsaed Alwakeel ${ }^{a}$ \\ ${ }^{a}$ Department of Physiology, Fac. of Vet. Med., Kafrelsheikh Univ. \\ ${ }^{b}$ Department of Anatomy\& Embryology, Fac. of Vet. Med., Kafrelsheikh Univ.
}

\begin{abstract}
Myostatin, a member of the transforming growth factor $\beta$ (TGF- $\beta$ ) superfamily, is a negative regulator of skeletal muscle growth in mammals. The loss or inhibition of myostatin signaling dramatically increases muscle mass. This study is aimed to detect single nucleotide polymorphisms (SNPS) in the myostatin (Mstn) gene and to associate measure their effect on mineral ( $\mathrm{Ca}$ and $\mathrm{P}$ ) and enzymatic (GOT and $A L P)$ serum levels in high and low meat producing Egyptian buffaloes. Mstn gene was amplified by PCR and subsequently, subjected to sequence analysis to identify different allelic patterns. The nucleotide sequence analyses revealed presence of a novel A31GSNP in Mstn1 locus at nucleotide number 50 before exon2. This SNP was synonymous as it is located in the non coding sequence and so no amino acid was changed. However, the sequences of the other three loci showed 100\% identity among the Egyptian buffaloes and as compare to the published sequences of buffalo (GenBank accession number, DQ091762). To identify whether A31G SNP is accompanied by change in serum levels of GOT, ALP enzymes, and $\mathrm{Ca}$ and $\mathrm{Ph}$, the levels of these enzymes and minerals were estimated in the serum of high and low meat producing Egyptian buffaloes at age of 2 year. The serum levels of ALP, GOT, $P$, and Ca were significantly increased in high meat producing buffaloes as compared to low meat producing animals. The results of this study can be enable breeders to do an accurate and earlier selection of high meat producing buffaloes on a genotype basis.
\end{abstract}

Keywords: Mstn gene, Egyptian buffalo, PCR, sequencing, SNPs. 


\section{INTRODUCTION}

Buffalo meat is well comparable to beef in many of the physicochemical, nutritional, functional properties and palatability attributes (Anjaneyulu et al., 1990). Egyptian buffalo represents an important part of animal production in Egypt (about $41 \%$ of total red meat production). However, because their growth rate and meat production are very poor when compared to foreign breeds, their meat production is insufficient for our needs (El-Magd et al., 2013; El-Nahas et al., 1998).

Myostatin (Mstn), a member of the transforming growth factor $\beta$ (TGF-ß) superfamily, is expressed in skeletal muscle (throughout life, from the early stages to late adulthood) and to some extent in fat tissue, heart and mammary tissues (Kambadur et al., 1997; McPherron and Lee, 1997). Mstn is a negative regulator of skeletal muscle growth in mammals (McPherron etal., 1997). Therefore, inhibition of this gene either naturally as in some cattle breeds or experimentally will cause sever increase in muscle growth (double-muscling). Myostatin knockout doubles the muscle mass of mice through both hypertrophy and hyperplasia of muscle fibers (Amthor et al., 2009).

Muscle metabolism can be assessed by biochemical techniques such as using aspartate aminotransferase (AST), alanine aminotransferase (ALT), alkaline phosphatase (ALP), glutamicoxaloacetic transaminase (GOT), lactate dehydrogenase (LDH) and creatine phosphokinase (CPK) enzymes activity (Latimer et al., 2006). Serum GOT content is normally low in level, but after extensive destruction of cardiac, hepatic, or skeletal tissues, this enzyme is librated into the blood at high levels (Harper, 1971). The estimation of serum GOT is widely used as diagnostic tool for liver injuries, myocardial infarctions, and skeletal muscle sympathies (Ogita and Markert, 1989). 
$\mathrm{Ca}$ is an important regulator of several body functions: intracellular signalling, muscle contraction, functioning of the nervous system, hormone and enzyme secretion and blood clotting. Calcium ions are believed to be critical for the fusion of myoblasts, as this process can be activated by calcium ionophores that carry calcium ions across cell membranes (David et al., 1981). Phosphorus (P) is an essential nutrient for the skeleton and $\mathrm{Ph}$ deficiency causes rickets in children (Pettifor, 2008) and osteomalacia in adults (Genant, 1993). Nevertheless, P deficiency is seldom due to a low dietary intake of $\mathrm{Ph}$, but rather to a genetic disorder.

It was hypothesized that mutation of Mstn can increase meat production in animals and this may be accompanied with increase enzymatic activity of GOT and AP and $\mathrm{Ca}$ and $\mathrm{Ph}$. Thus, we conducted this experiment to confirm this hypothesis.

\section{MATERRIALS AND METHODS}

\section{Animal source:}

Egyptian buffalo either male or female with different age and weight were used in this study. Animals were maintained at El-Nataff ElGidid Experimental Stations (Mahalet Mousa in Kafrelsheikh Governorate, Egypt) belonging to Animal Production Research Institute, Ministry of Agriculture. All records of growth traits (body weight, body height and average daily gain) for different growth periods (birth, 3, 6, 9, 12, 18 and 24 months) in Beheiry buffaloes were collected from farm records to be used for statistical analysis. For more details see our recent published paper (El-Magd et al., 2013). 


\section{DNA extraction:}

Blood samples from the jugular veins were collected, each sample was divided into two tubes, EDTA- tube (for DNA extraction) and plain tube (for measure blood parameters in serum). Blood samples were collected from jugular vein puncture into two vacutainer tubes, the first containing an anticoagulant (disodium EDTA) and kept in ice box. The genomic DNA was extracted using Gene JET genomic DNA extraction kit following the manufacturer protocol (Fermentas, \#K0721/USA) . The second tube is aplain tube to measure blood parameters in serum.

\section{Polymerase chain reaction (PCR)}

A partial sequence of myostatin was amplified by PCR using primers (Table 1) designed by Primer 3.0 software based on the published sequences of Indian buffalo (GenBank accession number,AY495587). To ensure primer sequence is unique for the template sequence, we checked similarity to other known sequences with BLAST (www.ncbi.nlm.nih.gov/blast/Blast.cgi).

Table (1): Primer sequences, PCR product size and localization of the selected three loci of myostatin gene.

\begin{tabular}{|c|c|c|c|c|}
\hline Locus & $\begin{array}{c}\text { Forward primer } \\
\left(15 \text { - }--^{\prime} / 3\right)\end{array}$ & $\begin{array}{c}\text { Reverse primer } \\
(15 \text {-.--'/3) }\end{array}$ & $\begin{array}{l}\text { Size } \\
\text { (bp) }\end{array}$ & Localiz--ation \\
\hline Mstn1 & $\begin{array}{l}\text { ATTCACTGGTGTGGCAAG } \\
\text { TTGTCTCTCAGA }\end{array}$ & $\begin{array}{l}\text { CCCTCCTCCTTACATACAA } \\
\text { GCCAGCAG }\end{array}$ & 620 & $\begin{array}{l}5^{\prime} \text { UTR, exon1, } \\
\text { intron1 }\end{array}$ \\
\hline Mstn2 & $\begin{array}{l}\text { GTTCATAGATTGATATGG } \\
\text { AGGTGTTCG }\end{array}$ & $\begin{array}{l}\text { ATAAGCACAGGAAACTGG } \\
\text { TAGTTATT }\end{array}$ & 550 & $\begin{array}{l}\text { Intron1, exon2, } \\
\text { intron3 }\end{array}$ \\
\hline Mstn3 & $\begin{array}{l}\text { TGAGGTAGGAGAGTGTTT } \\
\text { TGGG }\end{array}$ & $\begin{array}{l}\text { TCGAAATTGAGGGGAAGA } \\
\text { CC }\end{array}$ & 500 & $\begin{array}{c}\text { Intron3, exon3, } \\
\text { 3UTR }\end{array}$ \\
\hline
\end{tabular}

The PCR was carried out in areaction volume of $50 \mu \mathrm{L}$, containing $4.0 \mu \mathrm{L}$ DNA template (approximately $100 \mathrm{ng}), 1.0 \mu \mathrm{L}(0.20 \mathrm{mM}) \mathrm{dNTP}$, $5.0 \mu \mathrm{L}$ buffer, $3.0 \mu \mathrm{L}(2.5 \mathrm{mM}) \mathrm{MgCl} 2,2.0 \mu \mathrm{L} 10 \mu \mathrm{mol} / \mathrm{L}$ forward primer, $2.0 \mu \mathrm{L} \quad 10 \mu \mathrm{mol} / \mathrm{L}$ reverse primer, $1.0 \mu \mathrm{L} 10 \mathrm{X}$ Taq DNA 
polymerase (5 U/ $\mu \mathrm{L}$, Fermentas, \#K1071, European Union), and $32 \mu \mathrm{L}$ nuclease free water. Thermal cycling parameters were as follows: initial denaturation at $94^{\circ} \mathrm{C}$ for $5 \mathrm{~min}, 35$ cycles of amplification $\left(94^{\circ} \mathrm{C}\right.$ for $40 \mathrm{~s}$ for DNA denaturation, annealing $56^{\circ} \mathrm{C}$ for $1 \mathrm{~min}$, extension at $72^{\circ} \mathrm{C}$ for 1 min) and final extension at $72^{\circ} \mathrm{C}$ for $10 \mathrm{~min}$. The samples were held at $4{ }^{\circ} \mathrm{C}$. PCR products were resolved by electrophoresis on $2 \%$ agarose gel in $1 \mathrm{X}$ TBE, stained with ethidium bromide and visualized with UV light of gel documentation system (BiometraBiomedizinischeAnalytik, $\mathrm{GmbH})$.

\section{DNA sequencing:}

PCR products with expected size were purified using PCR purification kit following the manufacturer protocol (Jena Bioscience \# pp-201×s) to remove primer dimmers, primers, nucleotides, proteins, salt, agarose, ethidium bromide and other impurities (El-Magd et al., 2013). The purified PCR products were sequenced in automated sequencer (Applied Biosystem, USA). The Sequences were analyzed using the Chromas Lite 2.1 program (http://technelysium.com. au/? page_id=13) and the identity of the sequenced PCR product was examined using Blast search against GenBank database of Indian buffalo (http://blast.ncbi.nlm.nih.gov/Blast.cgi). The alignments, annotations and assembly of the sequences were performed using Geneious 4.8.4 software http://www.geneious.com/web/geneious/home.

\section{Spectrophotometric method for measurement of mineral level and enzymatic activities:}

Calcium was measured using calorimetric method following the manufacturer protocol (BioMerieux ${ }^{\circledR}$ - SA-English 3) (Mundy and Guise 1999). Phosphorus was measured using photometric method following 
the manufacturer protocol (Human Gessellschaft fur Biochemica and Diagonstic GmbH, D-65205 Wiesbaden - Germany) (Gamset et al.,1980). ALP was measured using kinetic method following the manufacturer protocol (EliTech) (Berth and Delanghe 2004). GOT was measured using kinetic method following the manufacturer protocol Human Gessellschaft fur Biochemica and Diagonstic GmbH, D-65205 Wiesbaden - Germany) (Schumann and Klauke 2003).

\section{RESULTS}

Three loci of the myostatin gene were amplified using PCR (Fig. 1).

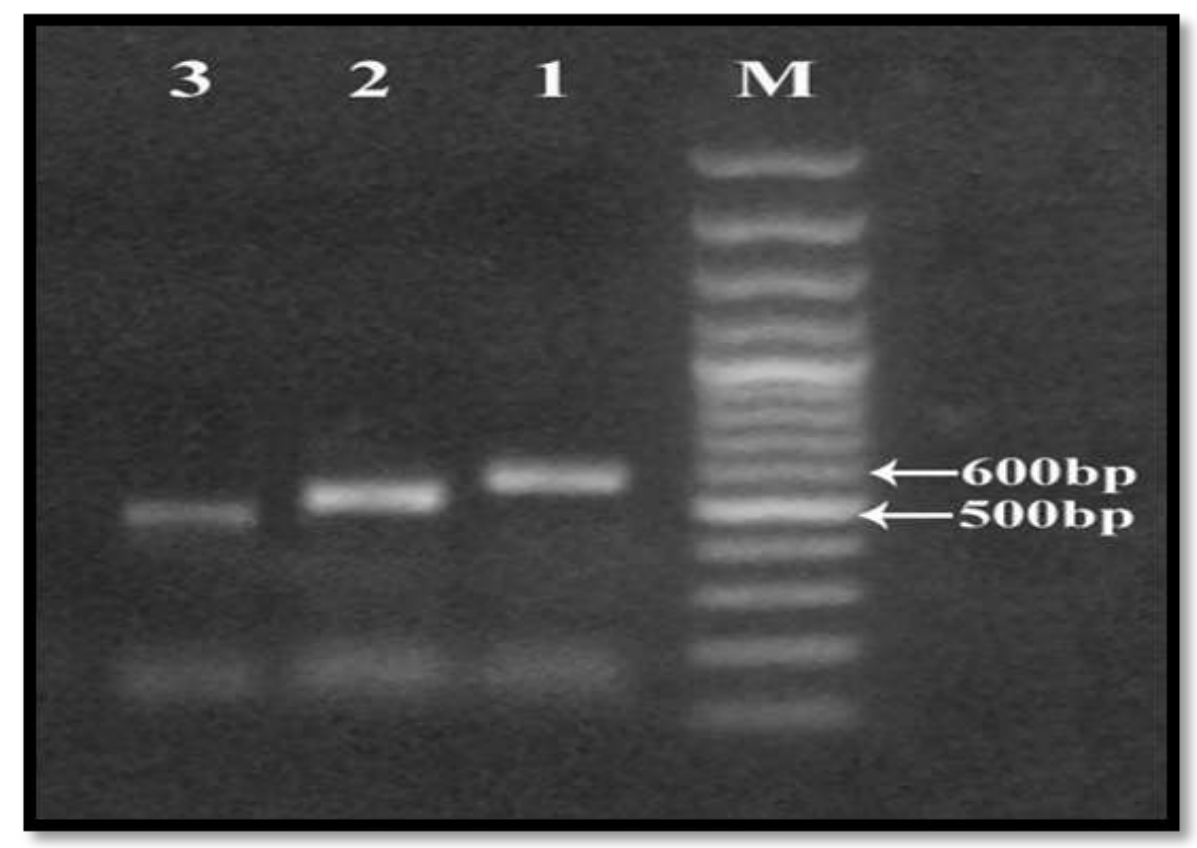

Fig.(1): Ethidium bromide stained agarose gel of PCR products representing amplification of the three loci of Mstn gene in Egyptian buffaloes: Mstn1 with size of 620bp (lane 1), Mstn2 with size of 550bp (lane 2), Mstn3with size 500bp (lane 3). M represents $1 \mathrm{kbp}$ ladder. 
After purification of these loci, sequencing was carried out in order to verify the identity of the PCR product and to detect any SNPs. This sequence was submitted to the GenBank database with accession number KJ123755. The nucleotide sequence analyses of these four loci revealed presence of a novel A31GSNP in Mstnl locus at nucleotide number 50 before exon2 (Fig. 2).This SNP was synonymous as it is located in the non coding sequence and so no amino acid was changed. However, the sequences of the other three loci showed $100 \%$ identity among the Egyptian buffaloes and as compare to the published sequences of buffalo (GenBank accession number, DQ091762). In all examined sequences, we found only homozygous genotype which either AA or GG and did not find the heterozygous (AG) genotype.

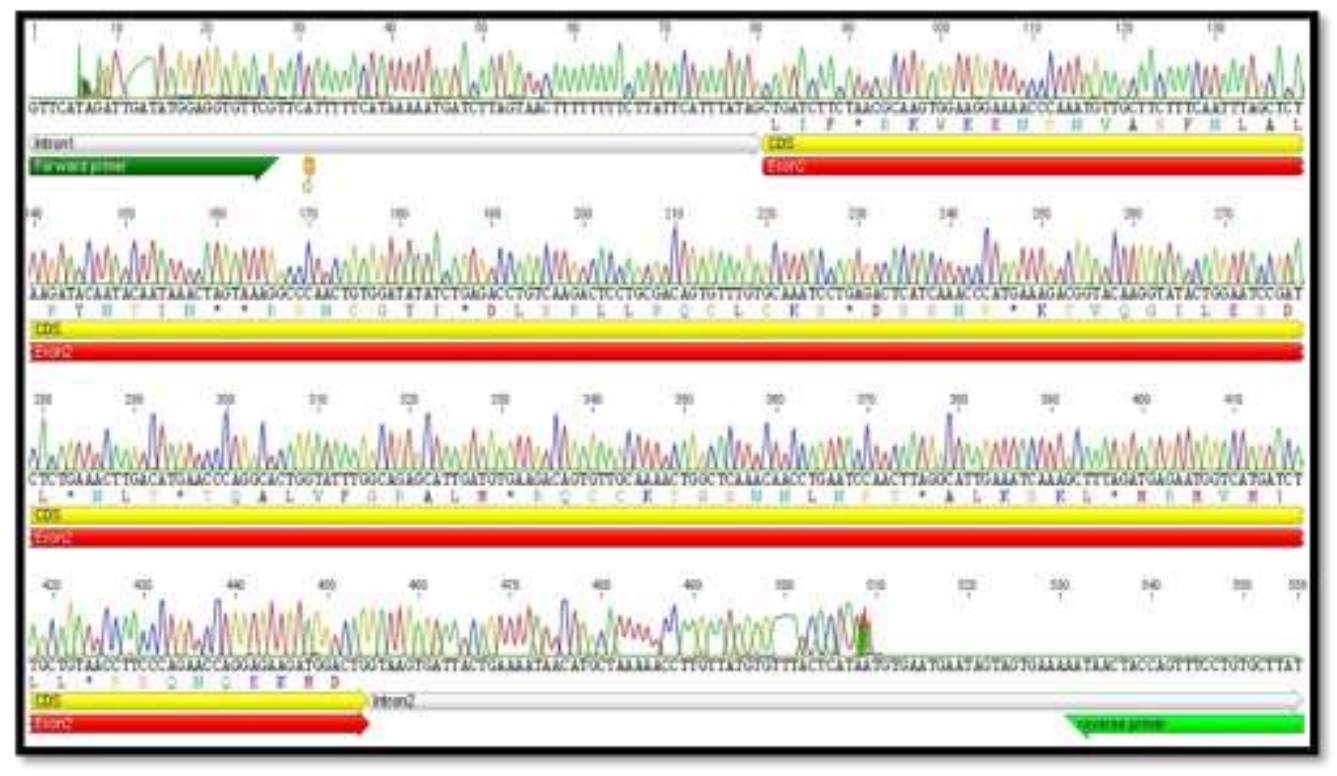

Fig.(2): Nucleotide sequences of Mstnl locus in Egyptian buffalo showed anovel synonymous A31G SNP in Mstn1 locus. The small yellow box indicates the position of SNP. 
Association between A31GSNP and serum levels of GOT, ALP, Ca and P:

To identify whether A31G SNP is accompanied by, change in serum levels of GOT, AP enzymes, and $\mathrm{Ca}$ and $\mathrm{Ph}$, the levels of these enzymes and minerals were estimated in the serum of high (GG) and low (AA) meat producing Egyptian buffaloes at age of 2 year.

The serum levels of both ALP and GOT enzymes were significantly increased in GG genotype buffaloes with higher meat production as compared to AA genotype animals with lower meat production (Table 2 and Fig.3).

Table (2): The effect of A31G SNP on ALP and GOT serum levels in 24 month old Egyptian buffaloes with high (GG) and low (AA) meat production.

\begin{tabular}{|c|c|c|c|c|}
\hline \multirow{2}{*}{ Enzyme } & \multirow{2}{*}{ Animal genotype } & \multicolumn{2}{|c|}{ Range } & \multirow{2}{*}{$\begin{array}{c}\text { Mean } \pm \text { Standard error of } \\
\text { mean }\end{array}$} \\
\hline & & Minimum & Maximum & \\
\hline \multirow{2}{*}{ ALP } & AA (control) & 105 & 205 & $159.5 \pm 5.87^{\mathrm{d}}$ \\
\hline & GG & 207 & 339 & $263.2 \pm 8.10^{\mathrm{a}}$ \\
\hline \multirow{2}{*}{ GOT } & AA (control) & 37 & 144 & $92.41 \pm 6.10^{\mathrm{c}}$ \\
\hline & GG & 144 & 230 & $197.1 \pm 4.90^{\mathrm{b}}$ \\
\hline
\end{tabular}

$\operatorname{LSD} 5 \%=0.128 ;$ LSD $1 \%=0.153$

Means with different letters in each column are significantly differed at $(\mathrm{p} \leq 0.05)$.

$\overline{\overline{\text { Kafrelsheikh Vet. Med. J. Vol. } 12 \text { No. } 1 \text { (2014) }}}$ 


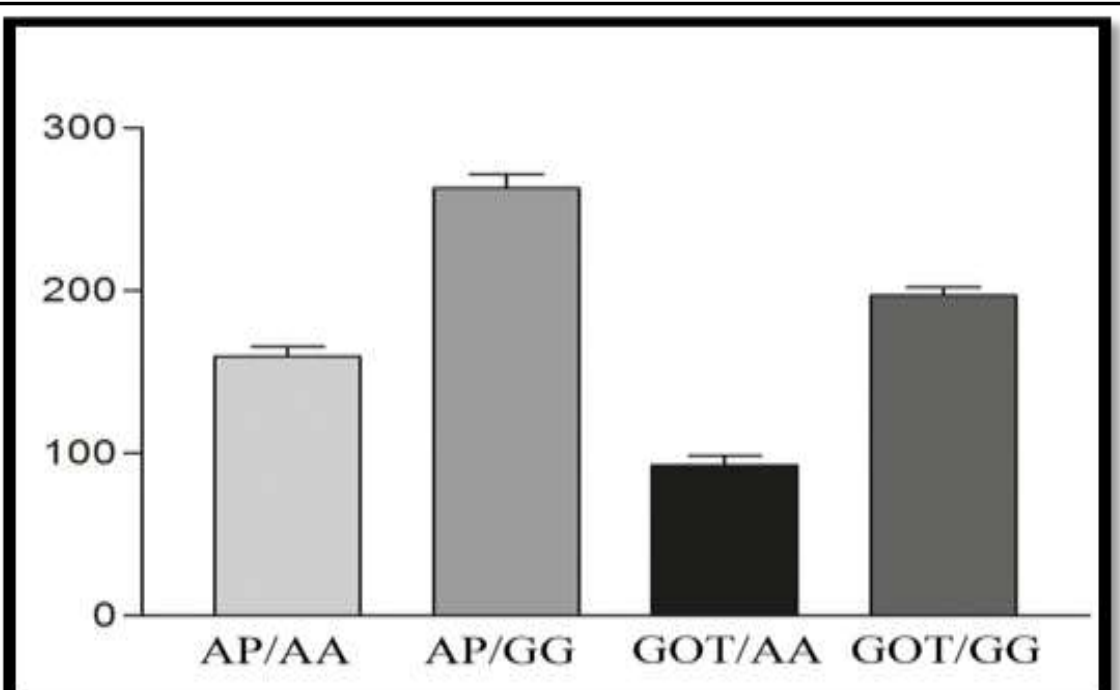

Fig. (3): Serum levels of ALP and GOT enzymes in high (GG) and low (AA) meat producing buffaloes.

The serum levels of both $\mathrm{P}$ and Ca were significantly increased in GG genotype buffaloes with higher meat production as compared to AA genotype animals with lower meat production (Table 3 and Fig.4).

Table (3): The effect of A31G SNP on P and Ca serum levels in 24 month old Egyptian buffaloes with high (GG) and low (AA) meat production.

\begin{tabular}{|c|c|c|c|c|}
\hline \multirow{2}{*}{ mineral } & \multirow{2}{*}{ Animal genotype } & \multicolumn{2}{|c|}{ Range } & \multirow{2}{*}{$\begin{array}{c}\text { Mean } \pm \text { Standard error of } \\
\text { mean }\end{array}$} \\
\hline & & $\overline{\text { Minimum }}$ & Maximum & \\
\hline \multirow{2}{*}{$\mathrm{P}$} & AA (control) & 3.57 & 4.61 & $4.08 \pm 0.05^{\mathrm{d}}$ \\
\hline & $\overline{G G}$ & 4.66 & 6.77 & $5.53 \pm 0.13^{\mathrm{c}}$ \\
\hline \multirow{2}{*}{$\mathrm{Ca}$} & $\overline{\mathrm{AA}(\text { control) }}$ & $\overline{77.1}$ & $\overline{111.06}$ & $\overline{9.15 \pm 0.26^{\mathrm{b}}}$ \\
\hline & GG & 11.22 & 15.55 & $13.49 \pm 0.27^{\mathrm{a}}$ \\
\hline
\end{tabular}

LSD $5 \%=0.126 ;$ LSD $1 \%=0.158$

Means with different letters in each column are significantly differed $(\mathrm{p} \leq 0.05)$.

$\overline{\text { Kafrelsheikh Vet. Med. J. Vol. } 12 \text { No. } 1 \text { (2014) }}$ 




Fig. (4): Serum levels of $\mathrm{P}$ and $\mathrm{Ca}$ in higher (GG) and lower (AA)meat producing buffaloes.

\section{DISCUSSION}

Myostatin (Mstn) limits the growth and development of all skeletal muscle in the mammals and so its inhibition dramatically increases muscle mass, due to hypertrophy and hyperplasia of muscle fibers, and produce double muscled animals (Amthor et al., 2009). Muscle metabolism in these animals is significantly higher than animals with low growth rate, and subsequently low meat production. Because muscle metabolism accompanied by altered activity of alkaline phosphatase (ALP), glutamic-oxaloacetic transaminase (GOT) (Latimer et al., 2006) and $\mathrm{Ca}$ and $\mathrm{P}$ (David et al., 1981), it is possible that the activities of these enzymes and minerals can be elevated in high meat producing animals. Therefore, this study is aimed to detect mutations [such as single nucleotide polymorphisms (SNPs)] in the Mstn gene and to associate their effect on enzymatic (GOT and ALP) and mineral (Ca and P) serum levels in high and low meat producing Egyptian buffaloes. 
To achieve this, Mstn gene was amplified by PCR and subsequently, subjected to sequence analysis to identify different allelic patterns. The nucleotide sequence analyses revealed presence of a novel A31G SNP in Mstn1 locus at nucleotide number 50 before exon 2. This SNP was synonymous as it is located in the non coding sequence and so no amino acid was changed. However, the sequences of the other three loci showed $100 \%$ identity among the Egyptian buffaloes and as compare to the published sequences of buffalo (GenBank accession number, DQ091762).

The serum level of ALP and GOT, can be used as a marker of the functional status of muscle tissue and varies widely in both pathological and physiological conditions. Previous studies have shown a conflict regarding to the relationship between muscle metabolic enzymes and both muscle growth and damage. There are two controversial points of veiw: the first stated that the metabolic enzymes are located inside the muscle fibers and their serum levels are only elevated when the muscle damaged or diseased, whereas the second theory denoted that elevation of metabolic enzymes in blood is mainly due to increase the muscle mass and activity. Several studies were in consistence with the first point of veiw. In human, an increase in metabolic enzymes may represent an index of cellular necrosis and tissue damage following acute and chronic muscle injuries (Brancaccio et al., 2007; Szumilak et al., 1998). The patients with progressive muscular dystrophy often show elevated serum levels of ALP and GOT (Srivastava et al., 2007). Subsequently, measurement of serum ALP and GOT is an important indicator of the occurrence of muscle cell necrosis and tissue damage due to disease or trauma (Brancaccio et al., 2007). 
On the other hand, the second points of view revealed that the large body animals as increasing in meat production can cause increasing in the serum levels of muscle metabolic enzymes. In agreement with this point of veiw, (Szabo et al., 2005) have found that the increased growth rate, mainly due to the muscular hypertrophy, changed the dynamics and the serum levels of some muscle metabolic enzymes such as ALP and GOT. In birds, the activity of muscle metabolic enzymes increased significantly in the heavy body weight compared with the light body weight. For example; serum levels of muscle metabolic enzymes was higher in domestic turkeys than wild turkeys (Bounous et al., 2000). This fact may be a direct consequence of the highly intensive selection for muscle development of the domestic turkey, leading to a significantly higher muscle mass paralleled with increased muscle fiber anaerobic capacity (Yost et al., 2002). The strongly increased muscle growth compromises skeletal muscle membrane integrity, leading to elevated serum activities of intracellular enzymes, such as ALP and GOT. Thus, the muscular metabolic activity and the physiological state of growth can be assessed by measuring serum levels of these muscle metabolic enzymes.The significant differences in the serum levels of these muscle metabolic enzymes among low and high body weight may be attributed to the genetic make-up of each weights (Shata, 2001).

$\mathrm{Ca}$ is an important regulator of several body functions: intracellular signalling, muscle contraction, functioning of the nervous system, hormone and enzyme secretion and blood clotting. Calcium ions are believed to be critical for the fusion of myoblasts, as this process can be activated by calcium ionophores that carry calcium ions across cell 
membranes (David et al., 1981). It is therefore can be elevated in animals with higher growth rate and meat production. In contrast, elevated $\mathrm{Ca}$ levels may be due to increased muscle activities rather than increased muscle mass. This hypothesis means that high growth rate and meat producing animals which are usually lazy should have a lower $\mathrm{Ca}$ level in their blood.

As a trial to find an answer for this paradox, we measured serum levels of ALP, GOT, Ca and P in A31G SNP of Mstn gene in Egyptian buffalo high and low growth rate and meat production. The serum levels of AP, GOT, $\mathrm{P}$, and $\mathrm{Ca}$ were significantly increased in high meat producing buffaloes as compared to low meat producing animals. Because all examined animals were healthy, our study supports the second theory and disagrees with the first theory. In consistence, higher muscle metabolic enzymes was shown in a rapidly growing turkey line, as compared to a slower growing one (Hassaan et al., 2008). Our results were in contrast to Wilson et al.,(1988) who found that serum muscle metabolic enzymes isn't increased in parallel with the total body or muscle mass (Wilson et al., 1988).

The results of this study can enable breeders to do an accurate and earlier selection of high meat producing buffaloes on a genotype basis.

\section{ACKNOWLEDGMENTS}

This study was funded by Science Technology Development Fund (STDF), Ministry of Scientific Research, Egypt. All experiments were conducted in the Biotechnology Lab, Faculty of Veterinary Medicine, Kafrelsheikh University, Egypt. 


\section{REFERENCES}

- Amthor, H., Otto, A., Vulin, A., Rochat, A., Dumonceaux, J., Garcia, L., Mouisel, E., Hourdé, C., Macharía, R., Friedrichs, M., Relaix, F., Zammit, P. S., Matsakas, A., Patel, K., Partridge, T., (2009). Muscle hypertrophy driven by myostatin blockade does not require stem/precursor-cell activity. Proceedings of the National Academy of Sciences of the United States of America. 106, 74797484.

- Anjaneyulu, A., Lakshmanan, V., Sharma, N., Kondaiah, N., (1990). Buffalo meat production and meat quality. Indian Food Packer. 44, 21-31.

- Bounous, D. I., Wyatt, R. D., Gibbs, P. S., Kilburn, J. V., Quist, C. $\boldsymbol{F}$., (2000). Normal hematologic and serum biochemical reference intervals for juvenile wild turkeys. $J$ Wildl Dis. 36, 393-6.

- Brancaccio, P., Maffulli, N., Limongelli, F. M., (2007). Creatine kinase monitoring in sport medicine. Br Med Bull. 81-82, 209-30.

- David, J. D., See, W. M., Higginbotham, C. A., (1981). Fusion of chick embryo skeletal myoblasts: Role of calcium influx preceding membrane union. Dev. Biol. 82, 297-307.

- El-Magd, M. A., Abbas, H. E., El-kattawy, A. M., Mokhbatly, A., (2013). Novel polymorphisms of the IGF1R gene and their association with average daily gain in Egyptian buffalo (Bubalus bubalis). Domestic animal endocrinology. 45, 105-110.

- El-Nahas, S., Abdel-Tawab, F., Zahran, M., Soussa, S., Rashed, M., Ali, S., (1998). Gene Mapping of River Buffalo by Somatic Cell hybridization. Eygpt J genet cytol. 27, 171-179. 
- Genant, H. K., (1993). Radiology of osteoporosis. In: Favus MJ (ed.) Primer on the metabolic bone diseases and disorders of mineral metabolism. New York, US: Raven Press, Ltd. 229-240.

- Harper, H. A., (1971). Review of physiological Chemistry Lange Medical Publications, los Altos,CA.

- Hassaan, S. F., El Salmoney, A. E., Fathi, M. M., (2008). relationship between triiodothyronine (T3) and insulin like growth factor( IGF1) hormone in egyptian local chicken during growth period. Poult. Sci. 28, 251-263.

- Kambadur, R., Sharma, M., Smith, T. P., Bass, J. J., (1997). Mutations in myostatin (GDF8) in double-muscled Belgian Blue and Piedmontese cattle. Genome Res. 7, 910-6.

- Latimer, K. S., Mahaffey, E. A., Prasse, K. W. Eds.), (2006). Clinical pathology.

- McPherron, A. C., Lee, S. J., (1997). Double muscling in cattle due to mutations in the myostatin gene. Proc Natl Acad Sci U S A. 94, 12457-61.

- Ogita, Z., Markert, C. L., (1989). Isozymes Structure, Function and Use in Biology and Medicine. John Wiely and Sons, New York. 853 875.

- Pettifor, J. M., (2008). What's new in hypophosphataemic rickets? Eur J Pediatr 167, 493-499.

- Shata, I. A. E., (2001): Physiological and biochemical studies on the skeletal muscles of Japanese quail. fac.of agric.,, Vol. PH.D. Ain Shams Univ., Cairo. 
- Srivastava, T., Chosdol, K., Chattopadhayay, P., Sarkar, C., Mahapatra, A. K., Sinha, S., (2007). Frequent loss of heterozygosity encompassing the hMLH1 locus in low grade astrocytic tumors. $J$ Neurooncol. 81, 249-55.

- Szabo, A., Mezes, M., Horn, P., Suto, Z., Bazar, G., Romvari, R., (2005). Developmental dynamics of some blood biochemical parameters in the growing turkey (Meleagris gallopavo). Acta Vet Hung. 53, 397-409.

- Szumilak, D., Sulowicz, W., Walatek, B., (1998). [Rhabdomyolysis: clinical features, causes, complications and treatment]. Przegl Lek. 55, 274-9.

- Wilson, B. W., Abplanalp, H., Buhr, R. J., Entrikin, R. K., Hooper, M. J., Nieberg, P. S., (1988). Inbred crosses and inherited muscular dystrophy of the chicken. Poult Sci. 67, 367-74.

- Yost, J. K., Kenney, P. B., Slider, S. D., Russell, R. W., Killefer, J., (2002). Influence of selection for breast muscle mass on myosin isoform composition and metabolism of deep pectoralis muscles of male and female turkeys. Poult Sci. 81, 911-7. 